\title{
The association of cognitive impairment with gray matter atrophy and cortical lesion load in clinically isolated syndrome
}

\author{
Sevda Diker ${ }^{\mathrm{a}, *}$, Arzu Ceylan Has ${ }^{\mathrm{b}}$, Aslı Kurne ${ }^{\mathrm{c}}$, Rahşan Göçmen ${ }^{\mathrm{d}}$, Kader Karlı Oğuz ${ }^{\mathrm{d}}$, \\ Rana Karabudak ${ }^{\mathrm{c}}$ \\ ${ }^{a}$ Department of Neurology, Faculty of Medicine, Near East University, Nicosia 99138, Cyprus \\ ${ }^{\mathrm{b}}$ Bilkent University, National Magnetic Resonance Research Center, Bilkent, Ankara, Turkey \\ ' Department of Neurology, Faculty of Medicine, Hacettepe University, Ankara, Turkey \\ ${ }^{\mathrm{d}}$ Department of Radiology, Faculty of Medicine, Hacettepe University, Ankara, Turkey
}

\section{A R T I C L E I N F O}

\section{Article history:}

Received 13 February 2016

Received in revised form

3 August 2016

Accepted 12 August 2016

\section{Keywords:}

Multiple sclerosis

Clinically isolated syndrome

Cognitive functions

Cortical lesion

Gray matter

\begin{abstract}
A B S T R A C T
Background: Multiple sclerosis can impair cognition from the early stages and has been shown to be associated with gray matter damage in addition to white matter pathology.

Objectives: To investigate the profile of cognitive impairment in clinically isolated syndrome (CIS), and the contribution of cortical inflammation, cortical and deep gray matter atrophy, and white matter lesions to cognitive decline.

Methods: Thirty patients with clinically isolated syndrome and twenty demographically- matched healthy controls underwent neuropsychologic assessment through the Rao Brief Repeatable Battery, and brain magnetic resonance imaging with double inversion recovery using a 3T scanner.

Results: Patients with clinically isolated syndrome performed significantly worse than healthy controls on tests that evaluated verbal memory, visuospatial learning and memory, and verbal fluency. Significant deep gray matter atrophy was found in the patients but cortical volume was not lower than the controls. Visual memory tests correlated with the volume of the hippocampus, cerebral white matter and deep gray matter structures and with cerebellar cortical atrophy. Cortical or white matter lesion load did not affect cognitive test results.

Conclusion: In our patients with CIS, it was shown that cognitive impairment was mainly related to cerebral white matter, cerebellar cortical and deep gray matter atrophy, but not with cortical inflammation, at least in the early stage of disease.
\end{abstract}

(c) 2016 Elsevier B.V. All rights reserved.

\section{Introduction}

Cognitive impairment may be present during the early stages of multiple sclerosis (MS) (Achiron and Barak, 2003) with a prevalence ranging from $40 \%$ to $70 \%$ (Amato et al., 2006). It has a dramatic impact on personal, social and occupational function (Amato et al., 2006). MS-related cognitive deterioration is characterized by involvement of recent memory, sustained attention, information processing speed, and executive function (Rao et al., 1991). The Brief Repatable Battery of Neuropsychological Tests (BRBN) assesses cognitive domains that are most frequently impaired in MS and incorporates tests of verbal memory, visual memory, attention, concentration, speed of information

\footnotetext{
* Corresponding author.

E-mail addresses: sevdaomrumdiker@gmail.com (S. Diker), arzuceylanhas@hotmail.com (A.C. Has), maslituncer@gmail.com (A. Kurne) gocmentr@yahoo.com (R. Göçmen), karlioguz@yahoo.com (K.K. Oğuz), rkbudak@gmail.com (R. Karabudak).
}

processing, and verbal fluency (Rao et al., 1991). Although cognitive profile has interpatient heterogenicity, information processing speed is generally accepted as the mostly affected cognitive domain in MS (DeLuca et al., 2004; Tekok-Kilic et al., 2007).

Recent studies showed that brain atrophy assesment was a better predictor of cognitive impairment in MS than lesion burden (Benedict et al., 2004; Bermel and Bakshi, 2006). Although the relationship between cognitive deterioration and subcortical white matter (WM) pathology remains controversial (Benedict et al., 2004; Rovaris et al., 2000; Rao et al., 1989), there is increasing evidence of a primary role of cortical pathology in determining cognitive disability (Tekok-Kilic et al., 2007; Portaccio et al., 2006; Benedict et al., 2006a,b). Gray matter (GM) atrophy appears to have unique, (Sanfilipo et al., 2006) if not greater (Dalton et al., 2004; Bakshi et al., 2005) clinical significance than WM lesions and/or volume. GM atrophy is more strongly related to cognitive decline, especially when the cerebral cortex is assessed (Benedict et al., 2006a,b; Amato et al., 2004). Besides cortical atrophy, cortical lesion load was recently shown to be 
associated with progression of cognitive disability in MS (Calabrese et al. (2012). Increased ability of detection of cortical lesions in MS by double inversion recovery (DIR) sequences has been shown previously (Wattjes et al., 2007).

In this study, we assessed the extent and the most affected domains of cognitive impairment and its probable correlations with GM pathology in a clinical cohort of patients with clinically isolated syndrome (CIS) who presented with a first episode suggestive of MS.

\section{Materials and methods}

\subsection{Participants}

Thirty patients with CIS were studied [20 women and 10 men, mean age \pm standard deviation (SD) $31.4 \pm 8.5$ years]. The recruited patients had been followed up at the neuroimmunology clinic of Hacettepe University Hospital between 2012 and 2014. McDonald's criteria were used for the diagnosis of CIS. Patients with visual or upper limb involvement that would interfere with neuropsychologic testing, other neurologic disease, major systemic disease, major psychiatric illness, drug or alcohol addiction, any drug use that could interfere with cognitive function were excluded from the study. All patients were relapse free and had not taken any steroids for at least 1 month before the assessment (mean disease duration \pm SD $11.8 \pm 15.5$ months; range, 1-76 months). Eight (26.7\%) of the 30 patients were under treatment with beta-interferons or glatiramer acetate at the time of study entry. For each patient, a neurologic evaluation including disability rating on the Expanded Disability Status Scale (EDSS) and cognitive assessment using the BRBN were performed within a week of magnetic resonance imaging (MRI) acquisition. None of the patients had any treatment procedure changes during this interval. The test performances and MRI results of the patients were compared with those of 20 demographically-matched healthy controls ( 7 men and 13 women, mean age \pm SD $32.25 \pm 8.58$ years) who were recruited among healthy volunteers with a normal neurologic examination and with no history of neurologic disorders. The study was approved by the Ethics Committee of the Faculty of Medicine of Hacettepe University, and written informed consent was obtained from all participating subjects.

\subsection{Clinical and neuropsychologic assessment}

Depression was evaluated and excluded with the Beck's Depression Scale (Beck et al., 1961). The performance on each test of the BRBN was assessed by applying the available Turkish normative values, which for each test provided a mean test score $( \pm S D)$ obtained from 106 healthy individuals who were grouped by sex, age $(15-30,31-45,46-60)$ and education level ( $<7$ years, 7-12 years, > 12 years) (Bingol and Tütüncü, 2010). In particular, we defined the failure of a test when the score was at least 2 SDs below the corresponding mean normative value. Patients who failed at least two tests were considered cognitively impaired, and those who failed fewer than two tests were considered cognitively preserved. In brief, the BRBN consists of the following subtests:

1. The Selective Reminding Test (SRT), (Ehrenreich, 1995) which tests for verbal learning and memory using a list of 12 words. From up to six test trials, a total learning score (SRT-TL) is achieved, plus after $25 \mathrm{~min}$, a score for delayed recall (SRT-DR) is generated.

2. The 10/36-Spatial Recall Test (SPART) (Boringa et al., 2001) measures visuospatial learning and memory. Participants try to recall the location of 10 checkers that are randomly placed on a $6 \times 6$ checkerboard. The sum of the correct responses in the three immediate recall trials (total learning, SPART-TL), and the delayed recall after $15 \mathrm{~min}$ (SPART-DR) are recorded.

3. The Symbol Digit Modalities Test (SDMT) (Smith, 1991) measures information processing speed, sustained attention, and concentration. Subjects are given $90 \mathrm{~s}$ to substitute symbols for numbers as part of a set code.

4. The Paced Auditory Serial Addition Test (3 s version; PASAT3) (Gronwall, 1977) examines sustained attention, working memory, and information processing speed by evaluating an addition task regarding acoustically presented digits at a rate of $3 \mathrm{~s}$ per digit.

5. Word List Generation (WLG), (Rao et al., 1991) which measures verbal fluency on semantic stimulus by evaluating the spontaneous production of words in a given category within $90 \mathrm{~s}$.

The BRBN, which has been translated and validated in Turkish, (Bingol and Tütüncü, 2010) was applied in a standardized, singletest session in the following order: SRT-TL, SPART-TL, SDMT, PASAT3, SRT-DR, SPART-DR, and WLG, and lasted for approximately 30-45 min.

\subsection{MR examination and analysis}

A cranial MRI examination of each participant was performed in the same week as the neuropsychologic examination using a 3T scanner (Magnetom, Trio Tim, Siemens) in the National MR Research Center (UMRAM, Bilkent University, Ankara). The MRI protocol included axial T1-weighted (W) (TR/TE; 500/10 msec), FLAIR (TR/TE/TI; 9000/97/2499.5 msec, slice thickness (ST)/interslice gap (IG): 4.0/0.8 mm), T2W (TR/TE; 4800/92 msec, ST/IG; 4.0/ $0.8 \mathrm{~mm}$ ) imaging. To better delineate the lesions, a sagittal doubleinversion recovery sampling perfection with application optimized contrasts using different flip angle evolution (DIR SPACE) sequence (TR/TE/TI: 7500/325/3000 msec, ST/IG; 1.12/0 mm, FOV: $215 \times 215$, matrix: $192 \times 192$ ) was also applied. The total MRI took about $30 \mathrm{~min}$. No medication or contrast agent was used.

We used Freesurfer version 5.3.0 (http://surfer.nmr.mgh.har vard.edu/) volumetric segmentation to obtain regional measures of cortical volumes $\left(\mathrm{mm}^{3}\right)$, including the removal of non-brain tissue (skull, eyeballs, and skin), with an automated algorithm with the ability to segment the whole brain without any user intervention, and cortical surface reconstruction methods. Fischl et al. (2002) previously described the automated procedures for volumetric measures of the different brain structures. The reconstructed cortical surface models for each participant were checked to confirm segmentation accuracy and regions with poor segmentation accuracy resulting from poor image quality or misregistration were excluded. Cortical surfaces were automatically parcellated and combined to constitute the average cortical volume for total GM and for frontal, temporal, parietal, and occipital lobes. Each patient's intracranial volume was used to normalize the constituted regions. The volume of $\mathrm{T} 1$ hypointense lesions was also calculated using Freesurfer. Each volume of region was normalized to each patient's intracranial total brain volume.

We used BrainVoyager QX 2.6 for Linux (http://www.brain voyager.com) to record the coordinations of each hyperintense WM and GM lesion on DIR SPACE imaging. The lesions were ranged using a bounding box in which all the intensities of voxels were fixed to a threshold for a clear visual distinction of lesions and parenchyma (http://support.brainvoyager.com/volumespace/ 107-volume-rendering/314-users-guide-masking-and-cutting.

html). The number and total volume of the voxel-of-interest (VOI) $s$, thus lesions visible on DIR SPACE imaging were calculated. In this way, it was aimed to determine the demyelinating hyperintense lesion load in respect to the number and volume of lesions in patients with CIS. 


\subsection{Statistical analysis}

As descriptive statistics for numerical measures mean \pm SD, median, minimum and maximum values were used. For qualitative measures, number and percent were given. The Shapiro-Wilk test was used to test whether distributions of measures of the patient and control group were normal. As the measures did not show a normal distribution, the 2 groups were compared using the Mann-Whitney $U$ test. Spearman's correlation and partial correlation analysis were used to show the relationship between measures with significance set at $\mathrm{p}<0.05$. Since the study covered multiple statistical analyses, False Discovery Rate (FDR) approach was applied for controlling statistical errors. FDR threshold was accepted to be 0.05 and the FDR method was performed with " fdrtool' package in R statistical software ( version 3.1.3). All statistical analyses were carried out using IBM-SPSS version 21.0.

\section{Results}

Main characteristics of patients with CIS and controls are detailed in Table 1.

\subsection{Neuropsychologic performance}

Only 2 patients out of the whole sample of 30 patients with CIS were diagnosed as having cognitive impairment if the reliable definition is used as abnormal test results in $\geq 2$ tests using a cutoff value of $\geq 2$ SDs below the mean of normative values. Rather than comparing 28 patients who were cognitively preserved with the two who were cognitively impaired, differences between the test results of the whole patient group and of the control group were analyzed (Table 2). Beck depression scores were worse in the patient group although it was below the cut-off level for mild depression in both groups. As expected, the normal controls performed better than patients with CIS in all neuropsychologic tests, although this difference was significant for SRT-DR, SPART-TL, SPART-DR and WLG ( $p<0.05$ for all measures). In the patient group, although age or age at disease onset was not found a predicting factor of any test result, education years had correlations with all tests. Disease duration had correlations with SPART-TL and SPART-DR tests. However, performances of SPART-TL, SPART-DR, SDMT and PASAT worsened in the control group as age progressed. Education years had correlations with WLG, SPART-TL and SDMT in the control group. Correlations of the test results with clinical and demographic data are summarized in Table 3.

\subsection{MRI findings}

MRI characteristics of the two groups are summarized in Table 4 . Volumes of each putamen, right caudate and right pallidum were lower, whereas the volume of the third ventricle was higher in the CIS group than in the control group ( $p<0.05$ for all measures). No differences in the cortical GM, cerebral WM, and thalamic volumes were found between each group ( $p>0.05$ for all measures). On DIR SPACE images, the mean WM lesion number was $10.50 \pm 7.459$ (mean $\pm S D$, range $0-31$ ) and the volume was $2.99 \pm 5.58 \mathrm{~cm}^{3}$ (mean \pm SD). Seven patients (23.3\%) showed demyelinating lesions in deep GM. WM lesion load or deep GM lesions had no relationship with age, age at disease onset or disease duration ( $p>0.05$ for all measures).

Cortical lesions on 3D DIR were detected in 23 (76.6\%) patients (Fig. 1). These lesions were either supra- or infratentorial, and mostly located in the frontal and temporoparietal cortices, respectively. The mean cortical lesion number was $5.6 \pm 5.75$ $($ mean $\pm S D)$ and volume was $223.13 \pm 374.21 \mathrm{~mm}^{3}$ (mean $\pm \mathrm{SD}$ );
Table 1

Demographic characteristics of study population ( ON : optic neuritis, TM : transverse myelitis, IgGOB: immunoglobulin G oligoclonal band, CSF: cerebrospinal fluid EDSS: Expanded Disability Status Scale).

\begin{tabular}{llll}
\hline Characteristics & CIS (n:30) & $\begin{array}{l}\text { Healthy con- } \\
\text { trols (n:20) }\end{array}$ & p value \\
\hline Female to male ratio & $20: 10$ & $13: 7$ & NS \\
Age, mean \pm SD(range), y & $31.4 \pm 8.5(19-$ & $32.2 \pm 8.6(20-$ & NS \\
Education years, mean \pm SD & $51)$ & $51)$ & \\
$\quad$ (range), y & $12.3 \pm 3.4(5-$ & $12.9 \pm 3.1(5-16)$ & NS \\
Disease duration, mean \pm SD & $11.8 \pm 15.5(1-$ & - & \\
$\quad$ (range), m & $76)$ & & \\
Age at disease onset, & $30.5 \pm 7.97(18-$ & - \\
$\quad$ mean \pm SD(range), $\mathbf{y}$ & $50)$ & & \\
Attack type, No. (\%) & $9(30)$ & - & \\
ON & $11(36.7)$ & & \\
TM & $6(20)$ & & \\
Brainstem/cerebellar & $4(13.3)$ & & \\
Cerebral & $28(93.3)$ & - & \\
IgGoBs in CSF, No.(\%) & & & \\
No. receiving therapy & $22(73.3)$ & - \\
None & $8(26.7)$ & & \\
Immunomodulatory & $0(0)$ & & \\
Immunosuppressive & $24(80)$ & & \\
EDSS score, No.(\%) & $6(20)$ & & \\
0 & & & \\
1 & & & \\
\hline
\end{tabular}

Table 2

Comparison of cognitive test scores of the groups.

\begin{tabular}{llll}
\hline Test & $\begin{array}{l}\text { CIS (n:30) Mean } \pm \text { SD } \\
\text { (range) }\end{array}$ & $\begin{array}{l}\text { Controls (n:20) Mean } \pm \text { SD } \\
\text { (range) }\end{array}$ & p Value \\
\hline Beck & $5.40 \pm 2.527(1-9)$ & $3.95 \pm 1.504(2-7)$ & $\mathbf{0 . 0 3 1}$ \\
SRT-TL & $51.63 \pm 7.388(33-65)$ & $55.55 \pm 5.306(47-69)$ & 0.101 \\
SRT-DR & $9.0 \pm 1.912(3-11)$ & $10.15 \pm 1.565(7-12)$ & $\mathbf{0 . 0 3 5}$ \\
SPART-TL & $16.03 \pm 4.635(9-27)$ & $19.10 \pm 4.012(11-26)$ & $\mathbf{0 . 0 1 3}$ \\
SPART-DR & $5.43 \pm 2.144(2-10)$ & $6.90 \pm 1.774(4-10)$ & $\mathbf{0 . 0 1 1}$ \\
SDMT & $42.90 \pm 11.923(20-68)$ & $48.45 \pm 13.516(20-75)$ & 0.178 \\
PASAT3' & $39.10 \pm 17.271(0-60)$ & $44.95 \pm 13.858(0-60)$ & 0.258 \\
WLG & $24.57 \pm 5.418(15-34)$ & $30.40 \pm 10.831(20-70)$ & $\mathbf{0 . 0 2 5}$ \\
\hline
\end{tabular}

age, age at disease onset or disease duration had no effect on these two measures ( $\mathrm{p}>0.05$ for all measures).

There was not any statistically significant correlation between cortical lesion number/volume and cortical GM volume ( $\mathrm{p}>0.05)$.

As summarized in Table 5, the patients with cortical lesions $(n=23)$ were found to have higher WM lesion numbers and volume ( $\mathrm{p}<0.01$ for all measures) when compared with patients who had no cortical lesions $(n=7)$. Cortical GM volume did not differ between the two groups ( $\mathrm{p}>0.05)$.

\subsection{MRI measures and cognitive test results}

We analyzed the volumetric correlations of the cognitive tests that showed significant differences in performance between patients with CIS and controls. In the patient group, SPART-TL performance had correlations with total GM volume $(\mathrm{p}<0.01)$, and total cortical GM volume, subcortical GM volume and cerebellar cortical volume ( $\mathrm{p}<0.05$ for all). When adjusted for age, disease duration and education years, none of these correlations remained significant $(\mathrm{p}>0.05)$. SPART-DR test performance significantly correlated with subcortical GM volume and cerebellar cortical volume ( $\mathrm{p}<0.01)$ and to a lesser extent with total GM, hippocampus, cerebral WM volume $(\mathrm{p}<0.05)$. When adjusted for age, disease duration and education years, correlations between SPART-DR and cerebral WM volume, cerebellar cortical volume, 
Table 3

Correlation of cognitive test results and demographical data.

\begin{tabular}{|c|c|c|c|c|c|c|}
\hline \multirow{2}{*}{$\begin{array}{l}\text { Test } \\
\mathbf{r} \\
\mathbf{p}\end{array}$} & \multicolumn{4}{|c|}{ CIS patients } & \multicolumn{2}{|l|}{ Controls } \\
\hline & Age & $\begin{array}{l}\text { Education } \\
\text { years }\end{array}$ & $\begin{array}{l}\text { Age at } \\
\text { onset }\end{array}$ & $\begin{array}{l}\text { Disease } \\
\text { duration }\end{array}$ & Age & $\begin{array}{l}\text { Education } \\
\text { years }\end{array}$ \\
\hline Beck & $\begin{array}{l}-0.022 \\
0.909\end{array}$ & $\begin{array}{l}-0.042 \\
0.825\end{array}$ & $\begin{array}{l}-0.053 \\
0.783\end{array}$ & $\begin{array}{l}-0.065 \\
0.733\end{array}$ & $\begin{array}{l}0.204 \\
0.387\end{array}$ & $\begin{array}{l}0.211 \\
0.373\end{array}$ \\
\hline SRT-TL & $\begin{array}{l}-0.254 \\
0.176\end{array}$ & $\begin{array}{l}0.370 \\
0.044\end{array}$ & $\begin{array}{l}-0.261 \\
0.164\end{array}$ & $\begin{array}{l}0.138 \\
0.467\end{array}$ & $\begin{array}{l}-0.420 \\
0.065\end{array}$ & $\begin{array}{l}0.085 \\
0.721\end{array}$ \\
\hline SRT-DR & $\begin{array}{l}-0.225 \\
0.232\end{array}$ & $\begin{array}{l}0.397^{*} \\
0.030\end{array}$ & $\begin{array}{l}-0.222 \\
0.239\end{array}$ & $\begin{array}{l}0.025 \\
0.896\end{array}$ & $\begin{array}{l}-0.184 \\
0.436\end{array}$ & $\begin{array}{l}-0.060 \\
0.801\end{array}$ \\
\hline SPART-TL & $\begin{array}{l}-0.206 \\
0.274\end{array}$ & $\begin{array}{l}0.550^{* *} \\
0.002\end{array}$ & $\begin{array}{l}-0.180 \\
0.342\end{array}$ & $\begin{array}{l}-0.399^{*} \\
0.029\end{array}$ & $\begin{array}{l}-0.554 \\
0.011\end{array}$ & $\begin{array}{l}0.532^{*} \\
0.016\end{array}$ \\
\hline SPART-DR & $\begin{array}{l}-0.304 \\
0.102\end{array}$ & $\begin{array}{l}0.549^{* *} \\
0.002\end{array}$ & $\begin{array}{l}-0.238 \\
0.204\end{array}$ & $\begin{array}{l}-0.432^{*} \\
0.017\end{array}$ & $\begin{array}{l}-0.508 \\
0.022\end{array}$ & $\begin{array}{l}0.241 \\
0.307\end{array}$ \\
\hline SDMT & $\begin{array}{l}-0.228 \\
0.226\end{array}$ & $\begin{array}{l}0.542^{* *} \\
0.002\end{array}$ & $\begin{array}{l}-0.248 \\
0.185\end{array}$ & $\begin{array}{l}-0.101 \\
0.597\end{array}$ & $\begin{array}{l}-0.526^{* *} \\
0.017\end{array}$ & $\begin{array}{l}0.478^{*} \\
0.033\end{array}$ \\
\hline PASAT3' & $\begin{array}{l}-0.353 \\
0.055\end{array}$ & $\begin{array}{l}0.704^{* *} \\
0.000\end{array}$ & $\begin{array}{l}-0.337 \\
0.068\end{array}$ & $\begin{array}{l}-0.151 \\
0.426\end{array}$ & $\begin{array}{l}-0.454 \\
0.044\end{array}$ & $\begin{array}{l}0.426 \\
0.061\end{array}$ \\
\hline WLG & $\begin{array}{l}-0.168 \\
0.374\end{array}$ & $\begin{array}{l}0.458^{*} \\
0.011\end{array}$ & $\begin{array}{l}-0.215 \\
0.254\end{array}$ & $\begin{array}{l}0.035 \\
0.854\end{array}$ & $\begin{array}{l}-0.324 \\
0.164\end{array}$ & $\begin{array}{l}0.721^{* * *} \\
0.000\end{array}$ \\
\hline
\end{tabular}

r: Spearman correlation coefficient.

${ }^{*} \mathrm{p}<0.05$.

$\mathrm{p}<0.01$.

Table 4

Comparison of volumetric measures of CIS patients and the controls.

\begin{tabular}{llll}
\hline & $\begin{array}{l}\text { CIS group Mean } \pm \text { SD } \\
(\mathbf{c m} 3)\end{array}$ & $\begin{array}{l}\text { Control group } \\
\text { Mean } \pm \text { SD }(\mathbf{c m} 3)\end{array}$ & p Value \\
\hline L cortical GM & $223.8 \pm 261.9$ & $232.1 \pm 370.6$ & 0.464 \\
R cortical GM & $221.5 \pm 254.6$ & $230.5 \pm 355.1$ & 0.440 \\
Total cortical GM & $443.6 \pm 513.4$ & $462.9 \pm 733.1$ & 0.383 \\
L caudate & $4.54 \pm 6.31$ & $3.66 \pm 0.49$ & 0.113 \\
R caudate & $3.47 \pm 0.60$ & $3.91 \pm 0.94$ & $\mathbf{0 . 0 1 7}$ \\
L putamen & $5.43 \pm 0.98$ & $6.31 \pm 0.86$ & $\mathbf{0 . 0 0 7}$ \\
R putamen & $5.33 \pm 0.93$ & $6.17 \pm 0.94$ & $\mathbf{0 . 0 0 8}$ \\
L pallidum & $1.70 \pm 0.24$ & $1.61 \pm 0.22$ & 0.476 \\
R pallidum & $1.39 \pm 0.20$ & $1.56 \pm 0.17$ & $\mathbf{0 . 0 0 5}$ \\
Total GM & $598.2 \pm 118.4$ & $633.1 \pm 83.6$ & 0.259 \\
3rd ventricle & $1.14 \pm 0.26$ & $0.82 \pm 0.21$ & $<\mathbf{0 . 0 0 1}$ \\
L cerebellar cortex & $48.7 \pm 5.98$ & $49.6 \pm 4.97$ & 0.332 \\
R cerebellar cortex & $50.2 \pm 5.34$ & $51.7 \pm 4.60$ & 0.243 \\
L cerebral WM & $242.7 \pm 480.7$ & $316.7 \pm 416.2$ & 0.303 \\
R serebral WM & $243.4 \pm 487.9$ & $223.1 \pm 188.1$ & 0.092 \\
L cerebellar WM & $14.4 \pm 2.54$ & $15.1 \pm 1.40$ & 0.227 \\
R cerebellar WM & $18.6 \pm 19.4$ & $15.1 \pm 1.24$ & 0.859 \\
L hippocampus & $4.10 \pm 0.42$ & $4.06 \pm 0.48$ & 0.890 \\
R hippocampus & $4.15 \pm 0.60$ & $4.30 \pm 0.45$ & 0.546 \\
\hline
\end{tabular}

R: right, L: left, WM : white matter, GM: gray matter.

and hippocampus volume remained significant $(\mathrm{p}<0.05$ for all measures). WLG and SRT-DR tests did not show any correlations with volumetric measures (Table 6). No relationship was found between cognitive test performances and WM lesion load or cortical lesion load ( $p>0.05$ for all measures) (Table 7 ). In the control group, after adjustment for age and education years, no positive correlation was found between cognitive test results and volumetric measures (Table 8). When FDR approach was applied to the unadjusted $\mathrm{p}$ values, correlation between SPART-DR and subcortical gray matter volume remained significant (FDR adjusted $\mathrm{p}$ : 0.04 ), while FDR adjusted p value was equal to 0.05 for the correlation between SPART-DR and cerebellar cortical volume, and higher than 0.05 for the rest of the correlations. When FDR correction was applied to $\mathrm{p}$ values adjusted for age, disease duration and education years, none of the correlations survived ( FDR adjusted $\mathrm{p}>0.05$ for all).

\section{Discussion}

The prevalence of cognitive impairment in our CIS group (6.6\%) was actually low when compared with rates in the literature, which range from 18\% to 57\%, (Feuillet et al., 2007; Khalil et al., 2011 ) and 40\% to 70\% (Rao et al., 1991; Benedict et al., 2006a,b) according to different reference criteria for CIS and MS, respectively. This might be due to the stringent criteria we used while analyzing the tests and the relatively short disease duration of our patients. In agreement with our findings, Khalil et al. (2011), who studied CIS patients with a mean disease duration of 0.2 years, found 2 out of 44 patients as cognitively impaired when using similar cut-off values. As a consequence, these small numbers precluded a comparison of cognitively-impaired versus cognitively-preserved patients, so the test results were compared between the whole CIS group and the control group.

Generally, information processing speed seems to be the most commonly affected cognitive domain in MS (DeLuca et al., 2004; Janculjak et al., 2002; Bergendal et al., 2007). However, the pattern of cognitive impairment varies as the disease progresses and the dominantly affected domain in the CIS population is conflicting. In our study, patients with CIS did not differ from the controls on the basis of PASAT and SDMT test performances, which measure the information processing speed. However, when compared with the controls, the patients with CIS scored significantly lower in visual memory, verbal memory, and semantic verbal fluency tasks, which were examined using SPART-DR and SPART-TL, SRT, and WLG tests, respectively. There are studies in the early stages of the disease with results that support our findings. In a group of 67 patients who were diagnosed as having probable MS, Achiron and Barak (2003) reported that the most frequently affected cognitive domain was visual learning and recall, followed by semantic verbal fluency. In our study, visual memory tasks were the most significantly impaired fields in the patient group when compared with the controls. Stage of the disease, which was relatively early in our patients, might be the reason for sparing of information processing speed with worsening visual memory, and cognitive profile is expected to widen as the disease progresses.

As regards to GM damage, we found significant deep GM atrophy without evidence of cortical atrophy in the CIS group when compared with the control group. Regional analysis of subcortical structures evidenced a significant atrophy that involved the right caudate, right pallidum, and bilateral putamen, and a significant enlargement of the third ventricle in the CIS group. Our findings of cortical GM sparing with prominent atrophy in deep GM are partly against the widely accepted conception that atrophy occurs from the earliest phase of disease, both at subcortical (Bergsland et al., 2012) and cortical levels (Calabrese et al., 2007a, b). However, there are studies in parallel with ours that found deep GM changes before prominent cortical atrophy existed (Bergsland et al., 2012; Henry et al., 2008).

In our patients with CIS, compared with the healthy controls, spatial recall tests were the most significantly worsened cognitive test performances. When we examined the volumetric correlations of worsening visuospatial abilities, we found that cerebellar cortical volume was one of the predictors of visuospatial memory in the patient group. Cerebellar cortical volume, although not statistically significant, was lower in the patient group. To our knowledge, this study is the first to explore the impact of cerebellar cortical pathology on visuospatial cognitive tasks in patients with CIS. Besides its well known motor functions, the role of the cerebellum in cognitive tasks and its reciprocal interactions with the cerebral cortex has been shown in functional MRI and 


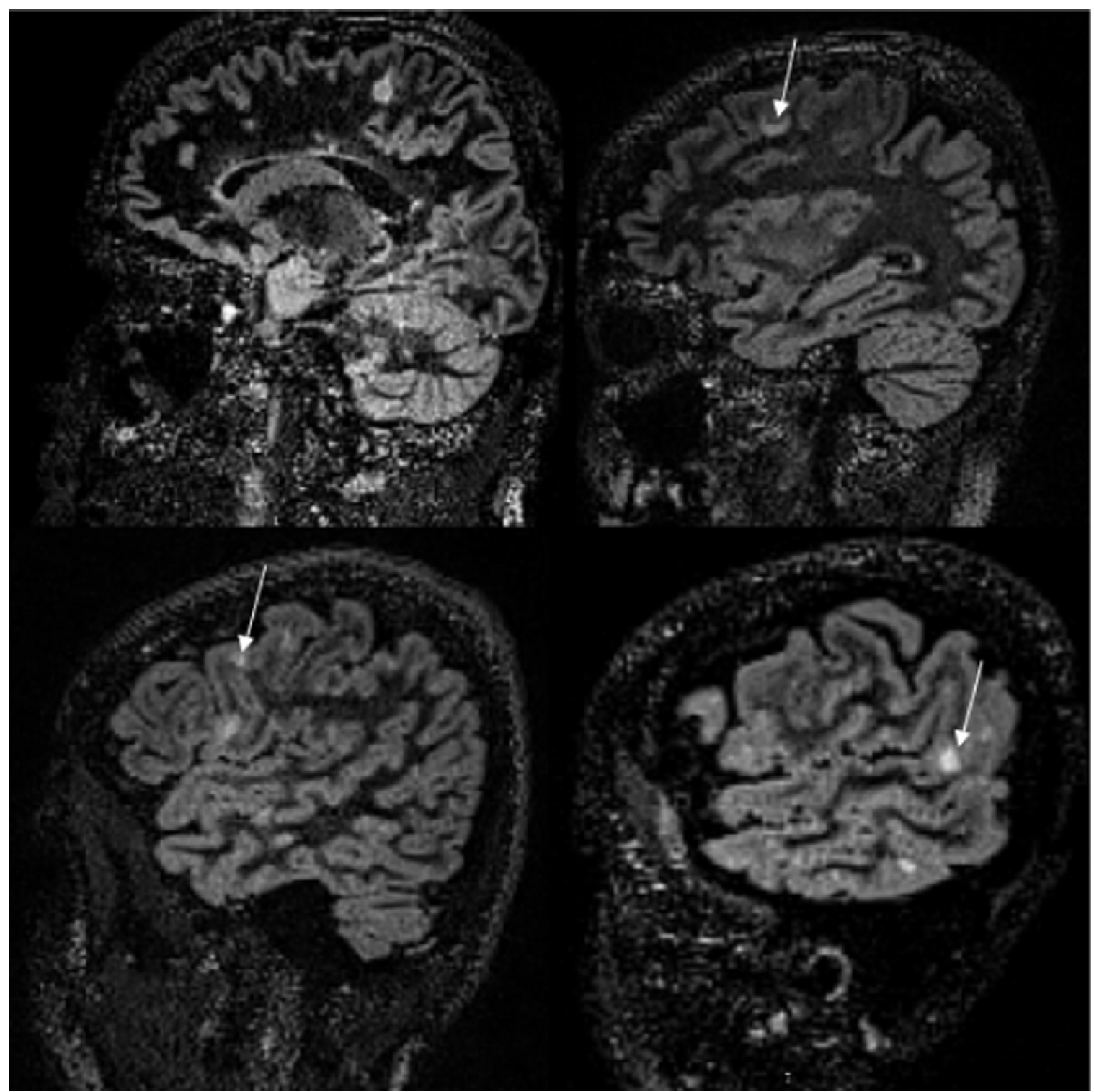

Fig. 1. Sagittal 3D DIR SPACE images obtained from four different patients show cortical/juxta-cortical hyperintense demyelinating lesions (arrows).

Table 5

Comparison of patients with and without cortical lesions.

\begin{tabular}{llll}
\hline & $\begin{array}{l}\text { Patients w/out cor- } \\
\text { tical lesion (n:7) }\end{array}$ & $\begin{array}{l}\text { Patients with cortical } \\
\text { lesion (n:23) }\end{array}$ & p Value \\
\hline $\begin{array}{l}\text { Age } \\
\text { Age at disease } \\
\text { onset }\end{array}$ & $33.1 \pm 9.8$ & $30.9 \pm 8.2$ & $>0.05$ \\
$\begin{array}{l}\text { Disease duration } \\
\text { WM lesion } \\
\text { number }\end{array}$ & $11.3 \pm 9.3$ & $30.0 \pm 7.6$ & $>0.05$ \\
$\begin{array}{c}\text { WM lesion vo- } \\
\text { lume (cm3) }\end{array}$ & $0.43 \pm 4.47$ & $12.0 \pm 17.2$ & $>0.05$ \\
$\begin{array}{c}\text { IgGOBs in CSF No. } \\
\text { (\%) }\end{array}$ & $7(100 \%)$ & $12.35 \pm 7.25$ & 0.006 \\
\hline
\end{tabular}

WM: white matter, IgGOB: immunoglobulin G oligoclonal band, CSF: cerebrospinal fluid.

diffusion tensor imaging studies (Salmi et al., 2010). The contribution of the cerebellum in memory, auditory, and language functions; visual locomotion and face perception; emotional processing; and social cognition has been implicated. (Sokolov et al., 2014; Stoodley and Schmahmann, 2009; Petersen et al., 1989;
Table 6

Correlation of cognitive test results and volumetric measures in patients with CIS after adjustment for age, disease duration and education years.

\begin{tabular}{lcllll}
\hline MRI Measure & & SRT-DR & SPART-TL & SPART-DR & WLG \\
\hline Total cortical GM & $\mathrm{r}$ & -0.086 & 0.158 & 0.104 & 0.141 \\
& $\mathrm{p}$ & 0.669 & 0.432 & 0.606 & 0.483 \\
Subcortical GM & $\mathrm{r}$ & -0.018 & 0.101 & 0.201 & -0.029 \\
& $\mathrm{p}$ & 0.927 & 0.617 & 0.315 & 0.885 \\
Cerebellar Cortex $(\mathbf{L}+\mathbf{R})$ & $\mathrm{r}$ & -0.039 & 0.351 & $\mathbf{0 . 4 7 9}$ & -0.058 \\
& $\mathrm{p}$ & 0.848 & 0.073 & $\mathbf{0 . 0 1 2}$ & 0.775 \\
Hippocampus $(\mathbf{L}+\mathbf{R})$ & $\mathrm{r}$ & -0.128 & 0.354 & $\mathbf{0 . 4 7 3}$ & 0.151 \\
& $\mathrm{p}$ & 0.525 & 0.070 & $\mathbf{0 . 0 1 3}$ & 0.453 \\
Cerebral WM $(\mathbf{L}+\mathbf{R})$ & $\mathrm{r}$ & -0.154 & 0.246 & $\mathbf{0 . 4 5 9}$ & -0.045 \\
& $\mathrm{p}$ & 0.443 & 0.216 & $\mathbf{0 . 0 1 6}$ & 0.825 \\
\hline
\end{tabular}

r: Spearman correlation coefficient-corrected, GM: gray matter, WM: white matter, L: left, R: right.

$$
\mathrm{p}<0.05 \text {. }
$$


Table 7

Correlation of cognitive test results and lesion load measures in patients with CIS.

\begin{tabular}{|c|c|c|c|c|c|c|c|c|}
\hline MRI measure & & SRT-TL & SRT-DR & SPART-TL & SPART-DR & SDMT & PASAT & WLG \\
\hline WM lesion number & $\begin{array}{l}\mathrm{r} \\
\mathrm{p}\end{array}$ & $\begin{array}{l}0.076 \\
0.690\end{array}$ & $\begin{array}{l}-0.196 \\
0.300\end{array}$ & $\begin{array}{l}-0.100 \\
0.600\end{array}$ & $\begin{array}{l}-0.060 \\
0.753\end{array}$ & $\begin{array}{l}0.053 \\
0.783\end{array}$ & $\begin{array}{l}-0.098 \\
0.606\end{array}$ & $\begin{array}{l}0.179 \\
0.343\end{array}$ \\
\hline WM lesion volume & $\begin{array}{l}\mathrm{r} \\
\mathrm{p}\end{array}$ & $\begin{array}{l}0.258 \\
0.169\end{array}$ & $\begin{array}{l}-0.098 \\
0.607\end{array}$ & $\begin{array}{l}-0.132 \\
0.487\end{array}$ & $\begin{array}{l}-0.157 \\
0.407\end{array}$ & $\begin{array}{l}0.066 \\
0.728\end{array}$ & $\begin{array}{l}-0.145 \\
0.445\end{array}$ & $\begin{array}{l}0.358 \\
0.052\end{array}$ \\
\hline Cortical lesion number & $\begin{array}{l}\mathrm{r} \\
\mathrm{p}\end{array}$ & $\begin{array}{l}0.284 \\
0.129\end{array}$ & $\begin{array}{l}0.134 \\
0.479\end{array}$ & $\begin{array}{l}-0.032 \\
0.866\end{array}$ & $\begin{array}{l}-0.029 \\
0.878\end{array}$ & $\begin{array}{l}0.009 \\
0.964\end{array}$ & $\begin{array}{l}-0.029 \\
0.878\end{array}$ & $\begin{array}{l}0.195 \\
0.302\end{array}$ \\
\hline Cortical lesion volume & $\begin{array}{l}\mathrm{r} \\
\mathrm{p}\end{array}$ & $\begin{array}{l}0.184 \\
0.331\end{array}$ & $\begin{array}{l}0.055 \\
0.774\end{array}$ & $\begin{array}{l}-0.040 \\
0.832\end{array}$ & $\begin{array}{l}-0.054 \\
0.778\end{array}$ & $\begin{array}{l}-0.007 \\
0.973\end{array}$ & $\begin{array}{l}-0.050 \\
0.794\end{array}$ & $\begin{array}{l}0.241 \\
0.199\end{array}$ \\
\hline
\end{tabular}

r: Spearman correlation coefficient, WM: white matter.

Table 8

Correlation of cognitive test results and volumetric measures after adjustment for age and education years in healthy controls.

\begin{tabular}{|c|c|c|c|c|c|c|c|c|}
\hline MRI measure & & SRT-TL & SRT-DR & SPART-TL & SPART-DR & SDMT & PASAT & WLG \\
\hline Total cortical GM & $\begin{array}{l}\mathrm{r} \\
\mathrm{p}\end{array}$ & $\begin{array}{l}-0.391 \\
0.109\end{array}$ & $\begin{array}{l}-0.530 \\
0.024\end{array}$ & $\begin{array}{l}0.232 \\
0.354\end{array}$ & $\begin{array}{l}0.020 \\
0.937\end{array}$ & $\begin{array}{l}-0.088 \\
0.729\end{array}$ & $\begin{array}{l}0.203 \\
0.420\end{array}$ & $\begin{array}{l}-0.024 \\
0.923\end{array}$ \\
\hline Subcortical GM & $\begin{array}{l}\mathrm{r} \\
\mathrm{p}\end{array}$ & $\begin{array}{l}-0.483 \\
0.042\end{array}$ & $\begin{array}{l}-0.022 \\
0.932\end{array}$ & $\begin{array}{l}0.364 \\
0.137\end{array}$ & $\begin{array}{l}-0.133 \\
0.598\end{array}$ & $\begin{array}{l}-0.269 \\
0.280\end{array}$ & $\begin{array}{l}0.015 \\
0.954\end{array}$ & $\begin{array}{l}-0.251 \\
0.316\end{array}$ \\
\hline Total GM & $\begin{array}{l}\mathrm{r} \\
\mathrm{p}\end{array}$ & $\begin{array}{l}-0.510 \\
0.031\end{array}$ & $\begin{array}{l}-0.527 \\
0.025\end{array}$ & $\begin{array}{l}0.311 \\
0.208\end{array}$ & $\begin{array}{l}-0.004 \\
0.987\end{array}$ & $\begin{array}{l}-0.153 \\
0.545\end{array}$ & $\begin{array}{l}0.204 \\
0.417\end{array}$ & $\begin{array}{l}-0.105 \\
0.677\end{array}$ \\
\hline Cerebellar Cortex $(\mathbf{L}+\mathbf{R})$ & $\begin{array}{l}\mathrm{r} \\
\mathrm{p}\end{array}$ & $\begin{array}{l}-0.556 \\
0.017\end{array}$ & $\begin{array}{l}-0.452 \\
0.059\end{array}$ & $\begin{array}{l}0.378 \\
0.122\end{array}$ & $\begin{array}{l}-0.050 \\
0.843\end{array}$ & $\begin{array}{l}-0.002 \\
0.994\end{array}$ & $\begin{array}{l}0.202 \\
0.422\end{array}$ & $\begin{array}{l}-0.154 \\
0.542\end{array}$ \\
\hline Hippocampus $(\mathbf{L}+\mathbf{R})$ & $\begin{array}{l}\mathrm{r} \\
\mathrm{p}\end{array}$ & $\begin{array}{l}-0.405 \\
0.096\end{array}$ & $\begin{array}{l}-0.416 \\
0.086\end{array}$ & $\begin{array}{l}-0.082 \\
0.748\end{array}$ & $\begin{array}{l}-0.157 \\
0.534\end{array}$ & $\begin{array}{l}-0.248 \\
0.322\end{array}$ & $\begin{array}{l}-0.165 \\
0.513\end{array}$ & $\begin{array}{l}0.135 \\
0.593\end{array}$ \\
\hline Cerebral WM $(\mathbf{L}+\mathbf{R})$ & $\begin{array}{l}\mathrm{r} \\
\mathrm{p}\end{array}$ & $\begin{array}{l}-0.342 \\
0.165\end{array}$ & $\begin{array}{l}-0.016 \\
0.948\end{array}$ & $\begin{array}{l}0.254 \\
0.308\end{array}$ & $\begin{array}{l}0.083 \\
0.743\end{array}$ & $\begin{array}{l}-0.008 \\
0.975\end{array}$ & $\begin{array}{l}0.067 \\
0.791\end{array}$ & $\begin{array}{l}-0.194 \\
0.441\end{array}$ \\
\hline
\end{tabular}

r: Spearman correlation coefficient- corrected, GM: gray matter, WM: white matter, L: left, R: right.

Grossman et al., 2000; Sokolov et al., 2010). However, in a study that investigated the contribution of cerebellar GM and WM volume to SDMT and PASAT tests in patients with MS, cerebellar atrophy was shown to have no direct effect on the test performances (Weier et al., 2014). In our study, we found a contribution of cerebellar cortical integrity to visual memory tasks in the CIS group and follow-up of our patients will show whether this impact increases with disease progression.

Atrophy of deep GM structures and its contribution to spatial recall test performances in patients with CIS were the other important findings of our study. In previous studies, deep GM atrophy was found to be predictive of cognitive decline in patients with MS (Benedict et al., 2013; Benedict et al., 2009). In our study, although not remaining significant after adjustment for confounding factors, SPART scores, especially SPART-DR, showed correlations with subcortical GMV.

Although in the literature thalamus and hippocampus atrophy have been shown to be related with slow verbal fluency, (Sumowski et al., 2009) we found no MRI correlations with WLG test results. Similarly, the other test that was scored more poorly by the patient group; SRT-DR, which evaluates long-term verbal memory, had no relation with volumetric measures.

We considered cortical lesion number/volume and cortical GM volume separately because the basis of GM atrophy in MS is not clearly understood. While primary damage of the GM, such as GM plaques that induce demyelination is one of the underlying mechanisms, GM atrophy can also be secondary to axonal transection in the WM plaques, normal appearing WM changes or GM in situ processes (Sepulcre et al., 2009; Bruck, 2005; Perry and Anthony, 1999). In parallel with this, we did not find any statistically significant correlation between cortical GM volume and cortical lesion number/volume.
We detected cortical lesions in 23 (76.6\%) of our patients. These patients had significantly higher WM lesion load when compared with patients who had no evidence of cortical lesions. Age, disease duration or age at disease onset showed no correlation with cortical lesion load. In the literature, prevalence of cortical lesions in the CIS population was found to be $37-40 \%$ using DIR-MRI (Calabrese et al., 2007a,b; Lucchinetti et al., 2011) and higher WM lesion volume and oligoclonal band positivity were detected as risk factors (Calabrese et al., 2007a,b). The high frequency of cortical lesions in our study group may be explained both by the presence of a significant number of patients with oligoclonal bands and their high WM lesion load.

As previously evidenced by Achiron and Barak (2003), the total lesion burden, whether in cortical or subcortical GM or WM, was not correlated with any cognitive task performances in patients with CIS. Our main results indicated that subcortical GM and WM volume were more closely related to neuropsychologic performance compared with lesion burden. However the pathologic specificity for 3D DIR to detect cortical lesions is $90 \%$, while its sensitivity is only $18 \%$ in total, $83 \%$ for mixed type lesions, $8 \%$ for intracortical lesions and $7 \%$ for subpial lesions (Geurts et al., 2005). The low detection rate of cortical lesions with DIR might be an explanation of the lack of a correlation between cortical lesion load and cognitive test results in our study.

Our study had limitations that should be taken into account. We did not analyse whether regional cortical or lobar volume affected cognitive function. In addition, our study was cross-sectional based on a modest sample of 30 patients. We are currently evaluating additional patients in order to obtain sufficient followup data. Another limitation is that, correlations between a number of cognitive test scores and brain volume/lesion measures were studied. This causes a multiple testing problem with such a sample 
size. In order to minimize this problem and make our study statistically stronger, we combined the MRI measures into bilateral measures where there was a high correlation between left and right side, allowing to reduce data dimensionality and we also applied FDR approach for the correlations.

In our study, we found that disease duration and educational years had contributions to some of the cognitive test scores, while age affected some volumetric measures of the brain. So while analyzing the correlations between test performances and volumetric measures, we controlled for these confounding factors. By this way, we confirmed the accuracy of the correlations we found. However a disadvantage of this method was that some correlations did not remain significant after adjustment which was the case for subcortical GM atrophy and its relation to worsening visuospatial memory. Also when we applied FDR approach to the adjusted p values, correlation between SPART-DR and subcortical gray matter volume did not remain statistically significant. The relatively small sample size may play a role in the loss of the statistical significance of these correlations after adjustment.

In conclusion, despite the high prevalence of cortical lesions in our patients, cognitive impairment was mainly related with cerebral WM and deep GM atrophy, and not with cortical inflammation, at least in the early stage of disease.

The significant WM lesion load of our patients did not interfere with the cognitive test results. It is our impression that the atrophy of both deep GM and WM, not the inflammatory lesions, is a sensitive marker of cognitive impairment. The main cognitive domain to be impaired in the patients with CIS was visual memory and its relation to cerebellar cortical measures was noteworthy and should be studied more extensively.

\section{Conflicts of interest}

The authors report no conflicts of interest.

\section{Acknowledgements}

The authors thank the National Magnetic Resonance Research Centre (UMRAM) for providing the MRI facility, and Anıl Dolgun and Özgür Tosun for their help in the statistical work.

\section{References}

Achiron, A., Barak, Y., 2003. Cognitive impairment in probable multiple sclerosis. J. Neurol., Neurosurg., Psychiatry 74, 443-6.

Amato, M.P., Bartolozzi, M.L., Zipoli, V., et al., 2004. Neocortical volume decrease in relapsing-remitting MS patients with mild cognitive impairment. Neurology 63, 89-93.

Amato, M.P., Zipoli, V., Portaccio, E., 2006. Multiple sclerosis-related cognitive changes: a review of cross-sectional and longitudinal studies. J. Neurol. Sci. 245, $41-46$.

Bakshi, R., Dandamudi, V.S., Neema, M., De, C., Bermel, R.A., 2005. Measurement of brain and spinal cord atrophy by magnetic resonance imaging as a tool to monitor multiple sclerosis. J. Neuroimaging : Off. J. Am. Soc. Neuroimaging 15 30S-45S.

Beck, A.T., Ward, C.H., Mendelson, M., Mock, J., Erbaugh, J., 1961. An inventory for measuring depression. Arch. Gen. Psychiatry 4, 561-571.

Benedict, R.H., Bruce, J.M., Dwyer, M.G., et al., 2006a. Neocortical atrophy, third ventricular width, and cognitive dysfunction in multiple sclerosis. Arch. Neurol. 63, 1301-1306.

Benedict, R.H., Cookfair, D., Gavett, R., et al., 2006b. Validity of the minimal assessment of cognitive function in multiple sclerosis (MACFIMS). J. Int. Neuropsychol. Soc. : JINS 12, 549-558.

Benedict, R.H., Ramasamy, D., Munschauer, F., Weinstock-Guttman, B., Zivadinov, R., 2009. Memory impairment in multiple sclerosis: correlation with deep grey matter and mesial temporal atrophy. J. Neurol., Neurosurg., Psychiatry 80, 201-206.

Benedict, R.H., Weinstock-Guttman, B., Fishman, I., Sharma, J., Tjoa, C.W., Bakshi, R.,
2004. Prediction of neuropsychological impairment in multiple sclerosis: comparison of conventional magnetic resonance imaging measures of atrophy and lesion burden. Arch. Neurol. 61, 226-230.

Benedict, R.H., Hulst, H.E., Bergsland, N., et al. Clinical significance of atrophy and white matter mean diffusivity within the thalamus of multiple sclerosis patients. Multiple Sclerosis. 2013.

Bergendal, G., Fredrikson, S., Almkvist, O., 2007. Selective decline in information processing in subgroups of multiple sclerosis: an 8-year longitudinal study. Eur. Neurol. 57, 193-202.

Bergsland, N., Horakova, D., Dwyer, M.G., et al., 2012. Subcortical and cortical gray matter atrophy in a large sample of patients with clinically isolated syndrome and early relapsing-remitting multiple sclerosis. AJNR Am. J. Neuroradiol. 33, 1573-1578.

Bermel, R.A., Bakshi, R., 2006. The measurement and clinical relevance of brain atrophy in multiple sclerosis. Lancet Neurol. 5, 158-170.

Bingol, A. YS, Tütüncü M., Cognitive dysfunction in multiple sclerosis in a Turkish cohort. In: Proceedings of the 20th Meeting of the European Neurological Society. 2010, Poster presentation.

Boringa, J.B., Lazeron, R.H., Reuling, I.E., et al., 2001. The brief repeatable battery of neuropsychological tests: normative values allow application in multiple sclerosis clinical practice. Mult. Scler. 7, 263-267.

Bruck, W., 2005. Inflammatory demyelination is not central to the pathogenesis of multiple sclerosis. J. Neurol. 252 (Suppl 5), v10-5.

Calabrese, M., Atzori, M., Bernardi, V., et al., 2007a. Cortical atrophy is relevant in multiple sclerosis at clinical onset. J. Neurol. 254, 1212-1220.

Calabrese, M., De Stefano, N., Atzori, M., et al., 2007b. Detection of cortical inflammatory lesions by double inversion recovery magnetic resonance imaging in patients with multiple sclerosis. Arch. Neurol. 64, 1416-1422.

Calabrese, M., Poretto, V., Favaretto, A., et al., 2012. Cortical lesion load associates with progression of disability in multiple sclerosis. Brain : A J. Neurol. 135, 2952-2961.

Dalton, C.M., Chard, D.T., Davies, G.R., et al., 2004. Early development of multiple sclerosis is associated with progressive grey matter atrophy in patients presenting with clinically isolated syndromes. Brain: J. Neurol. 127, 1101-1107.

DeLuca, J., Chelune, G.J., Tulsky, D.S., Lengenfelder, J., Chiaravalloti, N.D., 2004. Is speed of processing or working memory the primary information processing deficit in multiple sclerosis? J. Clin. Exp. Neuropsychol. 26, 550-562.

Ehrenreich, J.H., 1995. Normative data for adults on a short form of the Selective Reminding Test. Psychol. Rep. 76, 387-390.

Feuillet, L., Reuter, F., Audoin, B., et al., 2007. Early cognitive impairment in patients with clinically isolated syndrome suggestive of multiple sclerosis. Mult. Scler. 13, 124-127.

Fischl, B., Salat, D.H., Busa, E., et al., 2002. Whole brain segmentation: automated labeling of neuroanatomical structures in the human brain. Neuron 33 , 341-355.

Geurts, J.J., Pouwels, P.J., Uitdehaag, B.M., Polman, C.H., Barkhof, F., Castelijns, J.A., 2005. Intracortical lesions in multiple sclerosis: improved detection with 3D double inversion-recovery MR imaging. Radiology 236, 254-260.

Gronwall, D.M., 1977. Paced auditory serial-addition task: a measure of recovery from concussion. Percept. Mot. Skills 44, 367-373.

Grossman, E., Donnelly, M., Price, R., et al., 2000. Brain areas involved in perception of biological motion. J. Cognit. Neurosci. 12, 711-720.

Henry, R.G., Shieh, M., Okuda, D.T., Evangelista, A., Gorno-Tempini, M.L., Pelletier, D. 2008. Regional grey matter atrophy in clinically isolated syndromes at presentation. J. Neurol., Neurosurg., Psychiatry 79, 1236-1244.

Janculjak, D., Mubrin, Z., Brinar, V., Spilich, G., 2002. Changes of attention and memory in a group of patients with multiple sclerosis. Clin. Neurol. Neurosurg. 104, 221-227.

Khalil, M., Enzinger, C., Langkammer, C., et al., 2011. Cognitive impairment in relation to MRI metrics in patients with clinically isolated syndrome. Mult. Scler 17. 173-180.

Lucchinetti, C.F., Popescu, B.F., Bunyan, R.F., et al., 2011. Inflammatory cortical demyelination in early multiple sclerosis. New Engl. J. Med. 365, 2188-2197.

Perry, V.H., Anthony, D.C., 1999. Axon damage and repair in multiple sclerosis Philos. Trans. R. Soc. Lond. Ser. B, Biol. Sci. 354, 1641-1647.

Petersen, S.E., Fox, P.T., Posner, M.I., Mintun, M., Raichle, M.E., 1989. Positron emission tomographic studies of the processing of singe words. J. Cognit. Neurosci. 1, 153-170.

Portaccio, E., Amato, M.P., Bartolozzi, M.L., et al., 2006. Neocortical volume decrease in relapsing-remitting multiple sclerosis with mild cognitive impairment. J. Neurol. Sci. 245, 195-199.

Rao, S.M., Leo, G.J., Bernardin, L., Unverzagt, F., 1991. Cognitive dysfunction in multiple sclerosis. I. Frequency, patterns, and prediction. Neurology 41, 685-691.

Rao, S.M., Leo, G.J., Haughton St, V.M., Aubin-Faubert, P., Bernardin, L., 1989. Correlation of magnetic resonance imaging with neuropsychological testing in multiple sclerosis. Neurology 39, 161-166.

Rovaris, M., Filippi, M., Minicucci, L., et al., 2000. Cortical/subcortical disease burden and cognitive impairment in patients with multiple sclerosis. AJNR Am. J. Neuroradiol. 21, 402-408.

Salmi, J., Pallesen, K.J., Neuvonen, T., et al., 2010. Cognitive and motor loops of the human cerebro-cerebellar system. J. Cognit. Neurosci. 22, 2663-2676.

Sanfilipo, M.P., Benedict, R.H., Weinstock-Guttman, B., Bakshi, R., 2006. Gray and white matter brain atrophy and neuropsychological impairment in multiple sclerosis. Neurology 66, 685-692.

Sepulcre, J., Goni, J., Masdeu, J.C., et al., 2009. Contribution of white matter lesions 
to gray matter atrophy in multiple sclerosis: evidence from voxel-based analysis of T1 lesions in the visual pathway. Arch. Neurol. 66, 173-179.

Smith, A., 1991. Symbol Digit Modalities Test. Western Psychological Services, Los Angeles.

Sokolov, A.A., Gharabaghi, A., Tatagiba, M.S., Pavlova, M., 2010. Cerebellar engagement in an action observation network. Cereb. Cortex 20, 486-491.

Sokolov, A.A., Erb, M., Grodd, W., Pavlova, M.A., 2014. Structural loop between the cerebellum and the superior temporal sulcus: evidence from diffusion tensor imaging. Cereb. Cortex 24, 626-632.

Stoodley, C.J., Schmahmann, J.D., 2009. Functional topography in the human cerebellum: a meta-analysis of neuroimaging studies. Neurolmage 44, 489-501.

Sumowski, J.F.C.N., Wylie, G., Deluca, J., 2009. Cognitive reserve moderates the negative effect of brain atrophy on cognitive efficiency in multiple sclerosis. J. Int Neuropsychol. Soc. 15, 606-612.

Tekok-Kilic, A., Benedict, R.H., Weinstock-Guttman, B., et al., 2007. Independent contributions of cortical gray matter atrophy and ventricle enlargement for predicting neuropsychological impairment in multiple sclerosis. NeuroImage 36, 1294-1300.

Wattjes, M.P., Lutterbey, G.G., Gieseke, J., et al., 2007. Double inversion recovery brain imaging at 3T: diagnostic value in the detection of multiple sclerosis lesions. AJNR Am. J. Neuroradiol. 28, 54-59.

Weier, K., Penner, I.K., Magon, S., et al., 2014. Cerebellar abnormalities contribute to disability including cognitive impairment in multiple sclerosis. PloS One 9, e86916. 